The main interest in this case is that the patient's fits started only towards the end of a prolonged period of lactation, during which calcium losses would be expected to increase. ${ }^{3}$ We speculate that lactation was a major factor in inducing the convulsions since it may have reduced an already low plasma calcium concentration to epileptogenic levels. A further possibility is that she had a familial tendency to epilepsy that became manifest only in the hypocalcaemic state. Many neurologists do not perform routine biochemical screening in patients presenting with epilepsy: although it may not be justifiable economically to measure plasma calcium concentrations in every patient with epilepsy, we suggest that it is wise to exclude hypocalcaemia in any patient who presents with convulsions during lactation, even if there is a family history of epilepsy.

${ }^{1}$ Simpson JA. The neurological complications of hypoparathyroidism. Brain $1952 ; 75: 76-90$.

2 O'Donovan DK. The diagnosis of latent tetany with observations on the effect of calciferol. Br Med f 1948;ii :900-2.

${ }^{3}$ Fourman P, Royer P, Levell MJ, Morgan BM. Calcium metabolism and the bone. Oxford: Blackwell, 1968:62-4.

(Accepted 3 fune 1982)

Department of Neurology, Radcliffe Infirmary, Oxford

R A HARRAD, MA, MRCP, senior house officer (now at Western Ophthalmic Hospital, London NW1)

P G E KENNEDY, PHD, MRCP, registrar (now at National Hospital for Nervous Diseases, Queen Square, London WC1)

\section{Double-blind controlled study of primidone in essential tremor: preliminary results}

Essential tremor is a common, monosymptomatic disorder for which no predictable and completely satisfactory drug treatment is available. ${ }^{1}$ Primidone, a well-established anticonvulsant, has been reported to be highly effective, ${ }^{23}$ but this has been based on only uncontrolled clinical observations. We report the preliminary results of a doubleblind placebo-controlled study of primidone in essential tremor obtained using an objective recording technique.

\section{Patients, methods, and results}

We studied 11 patients with moderate to severe essential tremor aged 15-82 (mean 57) years. Mean duration of symptomatic tremor was 10.6 (range 4-24) years. The patients were not taking any other medication. Primidone and placebo were given in randomised order, according to a cross-over design, for five weeks each. Two patients received both primidone and placebo for two weeks only. Primidone was started at $62.5 \mathrm{mg}$ daily and increased by $62.5 \mathrm{mg}$ every day up to a maximum of $250 \mathrm{mg}$ three times a day.

At the end of each five-week regimen tremor was assessed under standardised conditions by using piezoresistive linear accelerometers (ENDEVCO $7265 / 10)$ attached at the dorsum of each hand, which were maintained outstretched and pronated with the arms supported to the wrists. Derived signals were computed off-line using a spectrum analyser, as described. ${ }^{4}$ Measurements were taken as the root mean square magnitude of acceleration and frequency $(\mathrm{Hz})$ of the dominant peak(s) in the spectrum. The unit of acceleration was referred to earth's gravity $\left(g=981 \mathrm{~cm} / \mathrm{s}^{2}\right)$. Only data derived from the hand that was more severely affected while placebo was being taken were used for statistical analysis. When the recordings of tremor had been completed blood samples were taken for assay of serum primidone and phenobarbitone concentrations. Statistical analysis of the data was performed using Wilcoxon's test for paired differences.

The frequency of the dominant peak of the tremor of the more affected hand ranged between 4.6 and $8.15 \mathrm{~Hz}$ (median $5.95 \mathrm{~Hz}$ ) and the magnitude from 11.02 to $675.29 \mathrm{mg}$ (median $30.55 \mathrm{mg}$ ). When the difference in magnitude was calculated as the absolute change value primidone was significantly superior to placebo $(p<0.01)$. In 10 patients the magnitude of tremor was lower when they received primidone compared with placebo (figure). The median reduction of the magnitude produced by primidone was $65.99 \%$ of the placebo value (range $12 \cdot 7-98 \cdot 7 \% ; p<0 \cdot 01$ ). No significant difference in the frequency of tremor was evident during primidone and placebo treatments.

Owing to dose-related side effects only seven patients achieved the maximum permitted dosage of primidone. The mean daily dosage for the whole group was 590 (range 125-750) mg daily. Serum concentrations of phenobarbitone ranged between 5 and $87 \mu \mathrm{mol} / \mathrm{l}$ (median $44 \mu \mathrm{mol} / \mathrm{l}$ ) and of primi- done between 18 and $100 \mu \mathrm{mol} / 1$ (median $49 \mu \mathrm{mol} / 1$ ). Side effects occurred with primidone in six patients and consisted of a variable combination of sedation, tiredness, nausea, and giddiness; these were attenuated with selfreduction of dosage. In two patients, who were severely affected, tremor was reduced by more than $90 \%$ of control values to within the range of physiological tremor (figure). These patients did not experience any side effects while taking the maximum doses of primidone.

Subsequently 10 patients were put on maintenance treatment with primidone and followed up for a minimum of six months while taking the drug. All maintained satisfactory improvement.

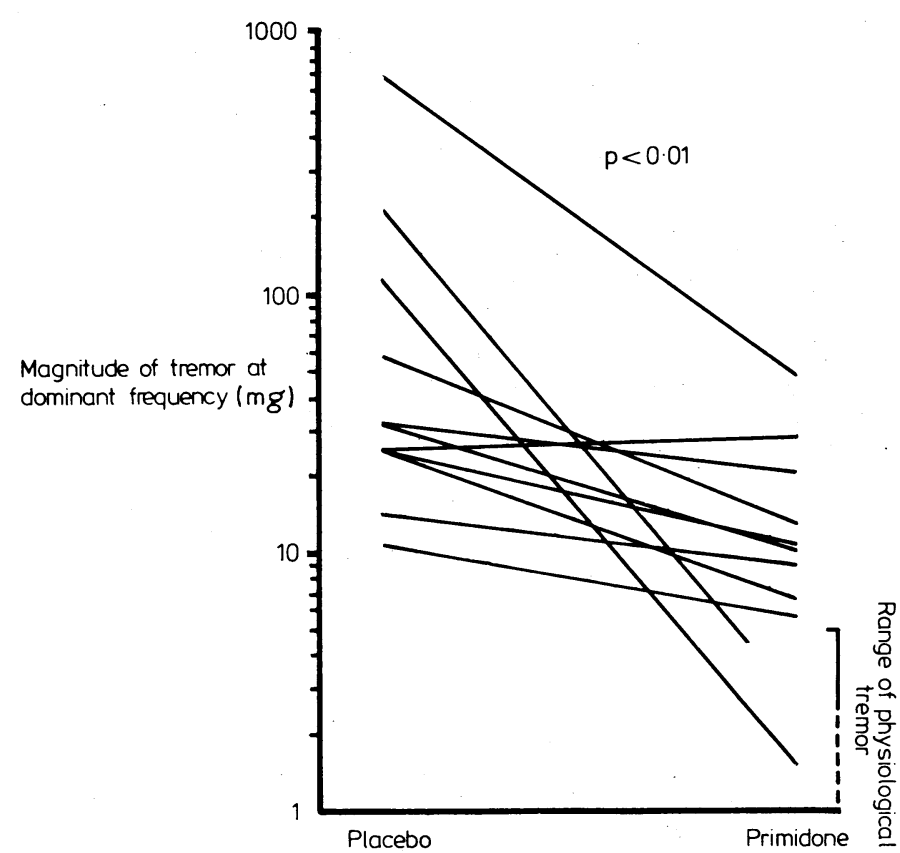

Effect of primidone on magnitude of hand tremor in 11 patients with essential tremor (figures are root mean squares).

\section{Comment}

Our results support the findings of others ${ }^{2} 3$ that primidone consistently improves essential tremor and may be of value in long-term symptomatic control of this condition. It may represent an alternative to propranolol, hitherto the drug of choice in this disorder, particularly in patients in whom beta-adrenoceptor-blocking drugs are contraindicated.

A previous study ${ }^{5}$ failed to show any significant effect of phenylethylmalonamide, a major metabolite of primidone, in essential tremor; it remains to be established, therefore, whether the tremorlytic effect of primidone is mediated by the parent drug itself or by derived phenobarbitone, or both.

Further studies are under way to determine whether a range of plasma concentrations of primidone or derived phenobarbitone may be established correlating with clinical effect.

${ }^{1}$ Murray TJ. Essential tremor. In: Barbeau A, ed. Disorders of movement. Lancaster: MTP Press, 1981:151-70.

2 O'Brien MD, Upton AR, Toseland PA. Benign familial tremor treated with primidone. Br Med $\mathcal{f} 1981 ; 282: 178-80$.

3 Chakrabarti A, Pearce JMS. Essential tremor: response to primidone. f Neurol Neurosurg Psychiatry 1981;44:650.

4 Calzetti S, Findley LJ, Gresty MA, Perucca E, Richens A. Metoprolol and propranolol in essential tremor: a double-blind controlled study. f Neurol Neurosurg Psychiatry 1981 ;44:814-9.

5 Calzetti S, Findley LJ, Pisani F, Richens A. Phenylethylmalonamide in essential tremor. A double-blind controlled study. F Neurol Neurosurg Psychiatry $1981 ; 44: 932-4$

(Accepted 28 May 1982)

Regional Centre for Neurology and Neurosurgery, Oldchurch Hospital, Romford, Essex

L J FINDLEY, MB, MRCP, consultant neurologist

MRC Neuro-otology Unit, National Hospital, Queen Square, London WC1N 3BG

S CALZETTI, MD, research fellow 